\title{
MÉTODOS PEDAGÓGICOS QUE INFLUENCIARAM O PLANEJAMENTO DAS AÇÕES EDUCATIVAS DOS ENFERMEIROS : REVISÃO BIBLIOGRÁFICA *
}

\section{PEDAGOGICAL AND CONCEPTUAL MODELS ACTING ON NURSING EDUCATION PLANNING: A BIBLIOGRAPHIC REVIEW.}

\author{
Maria José Moraes Antunes ** \\ Luiza Y. Okudaira Shigueno *** \\ Paolo Meneghin ****
}

ANTUNES, M.J.M. et al. Métodos pedagógicos que influenciaram o planejamento das ações educativas dos enfermeiros: revisão bibliográfica. Rev.Esc.Enf.USP., v.33, n.2, p. 165-74, jun. 1999.

\section{RESUMO}

Este trabalho busca identificar, em cinco periodos da História do Brasil, o uso, pelos enfermeiros, de metodologias pedagógicas nas ações educativas de saúde em enfermagem. Esta revisão procura resgatar a historicidade do processo educativo trilhado pela Enfermagem e propõe a incorporação, no planejamento das práticas educativas do enfermeiro, do uso de metodologias pedagógicas problematizadoras, concordando com os enfermeiros pesquisadores $e$ assistenciais que defendem aplicação de ações educativas que permitam ao aprendiz apropriar-se de conhecimento técnico aliado à conscientização política de si e do mundo, permitindo-lhe criar e recriar ações cotidianas.

NITERMOS: Educação em Saúde. Educação em Enfermagem.

\section{ABSTRACT}

This paper looks historically and critically at the pedagogical and conceptual models using by nurses during five cycles of Brazilian. History in nursing education. This article examines the patterns of nursing education while this historical time and suggests to include pedagogic models based on problem solving in nursing health practice.

UNITERMS: Health education. Nursing education.

\section{INTRODUÇÃO}

Este trabalho teve como ponto de partida as discussões ocorridas durante a disciplina "A esfera do planejamento na educação em saúde" do Curso de Pós Graduação da Universidade de São Paulo no segundo semestre de 1997.

A abordagem deste tema surgiu a partir do questionamento do resultado e das conseqüências do uso de metodologias pedagógicas que as enfermeiras utilizavam no aprendizado dos educandos pertencentes aos programas de grupos operativos de usuários dos serviços de saúde ou nos programas de educação continuada dos trabalhadores de enfermagem. A questão era pensar sobre quais concepções sustentavam estas metodologias, e se contribuiam para melhorar a condição humana do "educando" fosse ele um trabalhador ou um usuário com problemas de saúde ou se simplesmente eram momentos de imposição de repasse de conhecimentos a serem absorvidos por "pacientes ouvintes".

Trabalho apresentado à Disciplina "A esfera do planejamento na educação em saúde" - ENC-8524 do Programa de PósGraduação

** da Escola de Enfermagem da Universidade de São Paulo.

*** Enfermeira. Aluna do Programa de Pós-Graduação, nivel Doutorado, da Escola da Enfermagem da Universidade de São Paulo.

**** Enfermeira. Aluna do Programa de Pós-Graduação, nivel de Mestrado, Ela Escola de Enfermagem da Universidade de São Paulo.

Enfermeiro. Prof. Dr. do Departamento de Enfermagem Médico-Cirúrgica da Escola de Enfermagem da Universidade de São Paulo. Coordenador da Disciplina de Pós-Graduação "A esfera do planejamento na educação em saúde" - ENC-8524. E-mail:paolomen@usp.br 
Com o objetivo de verificar o processo educativo trilhado pela enfermagem, os autores, através de revisão bibliográfica e das discussões ocorridas em um seminário específico sobre o assunto, desenvolvido no transcorrer da disciplina, organizaram este trabalho, que consta de duas partes: a primeira discorre sobe as metodologias mais usadas na prática educativa na conformação de indivíduos sociais passivos ou ativos frente à realidade onde vivem. A segunda, busca averiguar a predominância destas metodologias nas práticas educativas dos enfermeiros, analisando-se cinco períodos históricos da sociedade brasileira.

\section{METODOLOGIAS MAIS USADAS NA PRÁTICA EDUCATIVA}

Em cada momento histórico, em cada sociedade, em cada realidade social, o processo educacional é portador de uma ideologia, e através de uma doutrina pedagógica leva o educando a integrar-se ao sistema em que vive. Cada opção pedagógica, quando exercida de maneira dominante, durante um periodo prolongado, tem conseqüências previsiveis sobre a conduta individual e também, o que é mais importante, sobre o comportamento da sociedade em seu conjunto. Entre as doutrinas pedagógicas mais utilizadas nas escolas encontram-se as formas pedagógicas de transmissão de conhecimentos. a tecnicista o $u$ de condicionamento e a da problematização da realidade (BORDENAVE, 1989).

A opção pedagógica mais tradicionalmente usada é a da transmissão de conhecimentos onde se parte da premissa de que as idéias e conhecimentos são os pontos mais importantes da educação e como conseqüência, a experimentação fundamental que o aluno deve viver para alcançar seus objetivos é a de receber o que o professor ou o livro the oferecem (BORDENAVE, 1989).

Assim o aluno é considerado uma página em branco, um receptáculo vazio onde novos conhecimentos, de origem externa, serão impressos. O objetivo é transmitir conceitos, idéias e procedimentos que o aluno recebe e adota por repetição. A mais importante crítica que se faz à pedagogia de transmissão é sua incapacidade de desenvolver as habilidades intelectuais de observação, avaliação, extrapolação e compreensão necessárias para criticar e recriar a realidade. As conseqüências do uso, de maneira prolongada e dominante, desta pedagogia em nivel individual são a passividade, a falta de atitude crítica, a relação dogmática com as fontes de informação, a valorização isolada do saber intelectual e a incapacidade de transformar a realidade. No âmbito coletivo e social obtêm-se grupos passivos e acríticos, adotando indiscriminadamente modelos e padrões de outras regiões, manipuláveis por comunicação de massa ou reproduzindo padrões historicamente estabelecidos, desvinculados do contexto social de sua realidade.

\section{Outra opção pedagógica largamente utilizada é a de condicionamento, conhecida} como conducionista ou tecnicista. Difere da de transmissão de conhecimentos por considerar como mais importante o aprender a fazer e não aprender a saber. Essa pedagogia advoga a reordenação do processo educativo de modo a torná-lo objetivo e operacional, priorizando a organização racional dos meios. Estão incluídos nessa proposta: o enfoque sistêmico, o microensino, a instrução programada e a especialização de funções. (BORDENAVE, 1989). O objetivo desta pedagogia é a formação de indivíduos eficientes, altamente técnicos, capazes de dar sua parcela de contribuição para o aumento da produtividade no sistema capitalista. Sua utilização forma individuos competitivos e individualistas. No âmbito coletivo produz grupos conformados com a realidade social, pouco criativos e dependentes de tecnologia e saberes externos.

A terceira opção pedagógica é a problematizadora, que pretende preparar o aluno como ser social, sujeito ativo, reflexivo, criativo e solidário, capaz de compreender e modificar sua realidade. Nesta proposta há o abandono da concepção do aluno receptor de informações ou do aluno reprodutor de técnicas ou padrões preestabelecidos, em beneficio da concepção do aluno construtor de seu conhecimento a partir da reflexão e indagação de sua própria prática e da sociedade onde vive. (BORDENAVE, 1989).

O mais importante na metodologia da problematização é desenvolver no grupo de alunos a capacidade de observar a realidade imediata ou circundante e a realidade global e estrutural, detectando seus problemas, condicionamentos e limitações e buscando nos conhecimentos científicos, recursos, tecnologias e novas formas de organização do trabalho. O aluno torna-se capaz de atuar e modificar a realidade observada, propondo e promovendo mudanças na prática social. A doutrina problematizadora tem como vantagens aproximar a cultura popular da cultura erudita, aliar o pensar e o fazer, favorecer a cidadania e o compromisso social. Possibilita assim, através da visão crítica da realidade a transformação das práticas pessoal, profissional e social.

"Não se quer aqui condenar as opções pedagógicas de transmissão ou de condicionamento. Elas são importantes no processo de ensinar, quando se faz necessário apreender padrões tecnológicos cientificamente comprovados. A superioridade da 
pedagogia de problematização está na sua contribuição para formar profissionais capazes de, na prática cotidiana, buscar um modo de " poderfazer-pensar reflexivo, crítico e transformador" (CHRISTÓFARO, 1988).

A respeito de métodos e técnicas educacionais na alfabetização de adultos, mas que podem ser também considerados para a prática educacional dos enfermeiros junto aos usuários e trabalhadores de enfermagem, Paulo Freire citado por GADOTTI (1997) afirma que "o fundamental é a clareza com relação à opção política do educador ou da educadora, que envolve princípios ou valores que ele ou ela assumir. Clareza em relação a um sonho possivel de ser concretizado. O sonho possivel deve estar sempre presente nas nossas cogitações em torno dos métodos e das técnicas. Há uma solidariedade entre eles que não pode ser desfeita".

Os educadores devem basear-se nesta afirmação de Paulo Freire para descobrir quais são os valores e desejos que os enfermeiros imprimem ao conteúdo de seus projetos de educação para a saúde e de educação continuada e como introjetam estes sonhos e desejos nos seus educandos. Assim, por exemplo, ao orientar famílias de idosos quanto à assistência de enfermagem domiciliária, o conteúdo e técnicas metodológicas condicionam e reforçam o idoso a assumir o papel socialmente determinado na sociedade brasileira de dependente dos familiares e consumidor de medicamentos ou buscam contribuir para que o idoso encontre, interagindo com sua família, alternativas para que tenha mais prazer e dignidade no seu ato cotidiano de viver? Por outro lado, ao preparar cursos de educação continuada, o conteúdo e as metodologias escolhidos pelas enfermeiras privilegiam os interesses da instituição empregadora, submetendo os trabalhadores ao rigor de rotinas e normas de trabalho extenuantes que nem sempre melhoram a qualidade dos cuidados de enfermagem prestados, mas que servem perfeitamente aos interesses da empresa na contenção de custos?

Essas questões trazem à tona o caráter político presente em toda ação educativa, independente de se ter ou não consciência disso. $\mathrm{E}$ as ações educativas não se dão ao acaso. Produzem e são reproduzidas no interior da sociedade e dos interesses materiais e imaginários em determinados momentos históricos, como descrito a seguir.

\section{METODOLOGIAS PREDOMINANTES NO PLANEJAMENTO DA FUNÇÃO EDUCATIVA DOS ENFERMEIROS E DA ENFERMAGEM AO LONGO DA HISTÓRIA DO BRASIL.}

Para esta análise foram utilizados, com adaptações, os quatro períodos históricos estabelecidos por FREITAG .(1986) e CHRISTÓFARO (1992), acrescidos de um quinto período, a década de noventa.

\subsection{Primeiro periodo: do Colonialismo à Primeira República (1500 a 1930).}

A sociedade brasileira, até o início das primeiras décadas do século XX, apresentava as seguintes características: organização voltada para garantir o modelo agro-exportador, sociedade política centrada nas grandes metrópoles, monocultura latifundiária não dependente de mãode-obra qualificada ou diversificada, reprodução da força de trabalho garantida pelo tráfico de escravos, instrução das elites em Portugal ou no seio das famílias opulentas, instrução e catequese dos silvícoas visando à aculturação e domesticação para o trabalho escravo. (CHRISTÓFARO, 1992).

Assim, a educação era usada para reforçar a submissão das classes exploradas, papel exercido pela Igreja Católica, assegurando o dominio dos portugueses sobre escravos, índios e colonos. Estas classes, sendo mão de obra farta, de baixo custo de manutenção e preparação, não exigiam de seus proprietários maiores investimentos na educação da mente e na preservação do corpo. Para estes bastava a expiação nesta terra para garantir a vida eterna.

Neste período, cabia à enfermagem, ainda não profissionalizada e predominantemente caritativa, desenvolver atividades mais voltadas para o alivio da alma do doente e alguns cuidados como os de higiene, de feridas; o preparo de chás, de alimentos; lavagem de roupas e do ambiente. Estes profissionais atuavam nas Santas Casas de Misericórdia, construídas para atender à população carente já que as classes abastadas cuidavam-se em casa, com médicos particulares. O trabalho da enfermagem estava sob a responsabilidade de congregações religiosas não havendo ensino de enfermagem formal e sistematizado.

Em 1832 surgem as primeiras escolas oficiais de formação em saúde com diferentes exigências para nelas ingressar. O curso superior de medicina, privativo para homens que tivessem mais de 16 anos, exigia que os candidatos soubessem latim, francês ou inglês, dominassem fisiologia racional e moral, aritmética e geometria. 
O curso de farmacêuticos exigia alunos com mais de dezesseis anos, dominio de francês ou inglês, aritmética e geometria "ao menos plana".

O terceiro curso oficial, o curso de parteiras, privativo para mulheres, tinha como exigências de ingresso a idade maior que dezesseis anos, saber ler e escrever corretamente e "apresentar um atestado de bons costumes passado pelo juiz de Paz da freguesia respectiva!" (Lei de 03 de Outubro de 1832) . Este curso foi suprimido em 1925 e foram criados cursos para as enfermeiras de maternidade, subordinados às faculdades de medicina (TEIXEIRA, 1989).

No século XIX, com o desenvolvimento do modelo industrial capitalista, desenvolve-se o conhecimento da medicina e os hospitais se transformam em local de cura e aperfeiçoamento da ciência médica. O saber médico transforma-se em poder, passando a comandar e a direcionar o processo de trabalho nos hospitais.

A enfermagem surge como profissão desenvolvendo conhecimentos e técnicas para cuidar dos pacientes, subordinada ao conhecimento médico. No seu desenvolvimento, o processo de trabalho da enfermagem, institucionalizado por Florence Nightingale na Inglaterra, incorporou a divisão técnica e social. (ALMEIDA;ROCHA, 1986).

Assim, cabia à Ladies Nurses, oriundas das familias de extratos sociais elevados, o desenvolvimento de atividades intelectuais, como ensino e supervisão. As Nurses, provenientes da população pobre, eram destinadas às tarefas de execução dos cuidados do paciente e do ambiente (BARBOSA, 1991).

Aos poucos, a enfermagem se institucionalizou em duas categorias: a de "enfermeiras diplomadas" que cumpriam o papel destinados Ladies Nurses de Florence Nightingale e a das enfermeiras práticas, incorporadas ao mercado de trabalho sem qualificação profissional formal (ALMEIDA;ROCHA, 1986) .

Assim, a pedagogia predominante no ensino de enfermagem era a de condicionamento: aprender a fazer sem questionar o porquê.

No Brasil, a institucionalização formal da divisão social do trabalho na enfermagem, surgiu com as primeiras escolas de enfermagem, tais como a "escola Profissional de Enfermeiros e Enfermeiras", mais tarde "Alfredo Pinto", em 1890; a "Escola da Cruz vermelha" em 1916 e a Escola de Enfermeiras anexa ao Hospital Geral de Assistência do Departamento Nacional de Saúde Pública (DNSP) em 1923, mais tarde "Escola de Enfermagem Ana Neri " (GOMES, 1991). As exigências para ingresso eram, além do atestado de bons antecedentes, saber ler e escre er $_{\mathrm{v}}$ corretamente e conhecer aritmética elementar. O conteúdo do curso era voltado, entre
Maria José Moraes Antunes et. al

outros tópicos, para noções práticas de propedêutica clínica, noções gerais de fisiologia, higiene hospitalar, curativos, pequena cirurgia, cuidados especiais a certas categorias de enfermos, aplicação de bálneo-terapias, administração interna e escrituração do serviço sanitário e econômico das enfermarias. (GOMES, 1991).

O artigo 3 do decreto 791 de 27/09/1890 estabelece: os cursos teóricos se efetuarão três vezes por semana, em seguida à visita s enfermarias e serão dirigidos pelos internos e inspetoras, sob fiscalização do médico e superintendência do diretor geral. (GOMES, 1991).

A Escola de Enfermagem ligada ao DNSP, posteriormente Escola de Enfermagem Ana Neri, surge no contexto de uma política de saúde que busca um projeto de educação sanitária. Assim, patrocinada pela Fundação Rockefeller, um grupo de enfermeiras americanas vem ao Brasil para colocar em prática um programa de ensino para o curso de enfermeiras do DNSP (GOMES, 1991). Desta forma, a enfermagem brasileira incorpora o modelo americano, que já havia adaptado o modelo Nightingaliano para suas necessidades tecnicistas, com predominio do "sistema de treinamento em serviço" onde "não havia interesse no crescimento intelectual das alunas". (GOMES, 1991). Este modelo indica um mínimo de conteúdo teórico e o uso cia concepção de condicionamento que valoriza a aprendizagem por repetição das técnicas.

A enfermagem brasileira, portanto, começa a institucionalizar-se conformando-se a um papel utilitarista, complementar e de submissão ao profissional médico, valorizando a técnica pela técnica.

Diferentemente da educação em enfermagem, na educação geral formal brasileira predominava a concepção humanista tradicional, a maioria a cargo de instituições religiosas, privilégio de poucos: em $1920,75 \%$ da população brasileira eram analfabetos (CHRISTÓFARO, 1992).

\subsection{Segundo Periodo: de 1930 a 1945.}

A partir deste período ampliou-se o crescimento do parque industrial brasileiro, buscando suprimir a necessidade de importações. Neste contexto surgiram a burguesia industrial urbana e a classe média, representada pelos funcionários públicos e empregados do comércio, com conseqüente aumento das demandas sociais (CHRISTÓFARO, 1992).

$\mathrm{Na}$ área de educação surgiu o Manifesto dos Pioneiros da Escola Nova (1932), defendendo a concepção humanista moderna no ensino. Foi criado, pelo presidente Vargas, o Ministério da Educação e 
Saúde; surgiram as primeiras universidades e o ensino primário tornou-se gratuito e obrigatório. (FREITAG, 1986). Foi introduzido, também, o ensino profissionalizante de encargo estatal e complementar, por determinação do Estado, pelas indústrias e pelos sindicatos. São implantados os liceus, "destinados a criar, na moderna juventude brasileira, um exército de trabalho para o bem da nação". (FREITAG, 1986).

O número de escolas técnicas industriais cresceu de 133, com 14.693 alunos, em 1933, para 1.368 com 65.485 alunos em 1945 (FREITAG, 1986)

A política estatal, aliada à emergente burguesia industrial, criou condições para assegurar maior produtividade no setor de produção qualificando o operário.

A saúde deste operário precisava. então ser preservada, já que havia sido feito um investimento neste trabalhador. Ao mesmo tempo, a classe trabalhadora buscava soluções para suas necessidades ligadas $\mathrm{s}$ condições de vida, direitos trabalhistas e necessidades individuais de saúde. Surgiram as caixas de Aposentadorias e Pensões (CAP's), mantidas com contribuições dos trabalhadores e empresários, cujos recursos destinavam-se à assistência dos seus beneficiários, inclusive assistência médica. O governo brasileiro não tinha influência sobre as CAP's até a década de 30, quando as transformou em Institutos de Aposentadoria e Pensão - os IAP's. Cada IAP cuidava das demandas de sua classe trabalhadora. Havia inúmeros IAP's, como os Institutos de Aposentadoria e Pensão dos Inclustriários (IAPI), dos comerciários (IAM, dos bancários (IAPB), entre outros.

Como a indústria e o comércio brasileiros já estavam em franca expansão, os institutos com maior número de trabalhadores se expandiram e entre outros beneficios, construiram e mantiveram hospitais para atender às necessidades de seus associados.

Assim, o capitalismo que se instalava tinha necessidade do corpo do trabalhador como instrumento de trabalho e cabia à medicina sua manutenção e restauração. A ampliação do número de hospitais, sedimentava-se a divisão social do trabalho no hospital: o médico, antes exercendo profissão liberal nos domicílios incorpora-se aos hospitais com a função de determinador das ações (dominador). A enfermagem assumiu o papel de executora das ações (subordinada), conformada a uma prática voltada para a disciplina e moral rigidas, complementares ao profissional médico, como modelo voltado à recuperação de corpos individuais para o trabalho.

A educação em enfermagem, no período, manteve-se voltada para condicionar (teoria do condicionamento) o pessoal de enfermagem a aprender técnicas, para cumprir rapidamente o papel que se esperava dele: atender à demanda dos cuidados necessários "aprendendo passo a passo a maneira de executar um procedimento, nas sem a necessidade de apreender o porquê de tal procedimento". (ALMEIDA;ROCHA, 1986).

Neste periodo, o analfabetismo e a baixa escolaridade predominavam na maioria dos que exerciam a enfermagem. Além disto, o trabalho gratuito ou de remuneração mínima, que as religiosas e laicas exerciam nos hospitais, reduziam o acesso dos "enfermeiros diplomados" ao mercado de trabalho (ALCANTARA, 1963).

A educação ou adestramento dos trabalhadores de enfermagem nos hospitais, a cargo de médicos e religiosas, enfatizava os resultados comportamentais, utilizando a pedagogia do condicionamento de maneira primitiva. Assim, ao profissional de enfermagem não era exigido domínio do saber teórico ou dos conhecimentos filosóficos que sustentavam a sua prática: bastava cumprir fiel e obedientemente as técnicas e prescrições médicas. O prêmio por tal comportamento não era um diploma formal de qualificação em enfermagem que the garantisse identidade profissional e acesso ao mercado de trabalho, mas a promoção de limpador de chão a ministrador de medicamentos...

O trabalhador de enfermagem desenvolvia um saber prático, dissociado da realidade social. Por não possuir força material, cultural e politica capaz de criticar e questionar a exploração a que era submetido, tornou-se dependente e conformado com o sistema vigente, perpetuando-se como classe dominada, explorada e desconsiderada. nos seus direitos, situação aliás não muito diferente dos atendentes de enfermagem dos anos noventa.

\section{3 - Terceiro Periodo: de 1945 a 1964.}

Surgiu no País, com a crise econômica decorrente do fim da Segunda Guerra Mundial, o "Estado Populista Desenvolvimentista", marcado pela aceleração e diversificação do processo de substituição de importações, a expansão da indústria nacional e o empobrecimento da classe média.

Subsistiam dois grupos no poder: o constituído pelos intelectuais da classe média, forças armadas e profissionais liberais (populistas) e o anti-populista, compreendido por grandes parcelas da classe média, da burguesia nacional, do capital estrangeiro monopolista e das antigas oligarquias. (FREITAG, 1986).

A Lei de Diretrizes e Bases da Educação Nacional e a Campanha da Escola Pública em 1961 que normatizavam a Constituição de 1946, fazem algumas concessões à classe operária e camponesa. 
Há extensão da rede escolar gratuita (primário e secundário), criam-se cursos técnicos, de nível médio, profissionalizantes (contabilidade, normal, comercial) a cargo da rede escolar privada, de dificil acesso A classe baixa. No entanto, em 1964, somente $2 / 3$ das crianças de 7 a 14 anos estavam matriculados em escolas e 3,3 milhões não tiveram acesso ao ensino (CHRISTÓFARO, 1992). Além disso, de cada 1.000 crianças que entravam no curso básico, em 1960, só 56 chegavam A universidade. Os demais ficaram pelo caminho, quer por deficiência das escoas ou por dificuldades financeiras, e foram se inserir no mercado de trabalho, inclusive no de saúde, sem nenhuma qualificação profissional. Dos 56 jovens que chegavam A universidade, 88,5\% pertenciam à classe alta. (FREITAG, 1986).

O sistema educacional reproduzia, assim, os interesses das classes dominantes. Os três níveis de ensino preparavam sua cliente a para as hierarquias profissionais estabelecidas na sociedade. $\mathrm{O}$ trabalho intelectual e de mando, de melhor remuneração, era reservado aos filhos cia classe alta, oriundos das universidades, em sua maioria públicas e gratuitas. O trabalho técnico qualificado, de média remuneração. cabia aos filhos da classe média e pobre que conseguissem pagar seu ensino. Restava para os de origem pobre, o trabalho assalariado, pesado, repetitivo e manual, sem exigência de qualificação ou com pouca qualificação profissional.

A Lei 775 de 1949 que dispunha sobre o ensino de enfermagem no país, refletindo esta estratificação estabelecida pela sociedade, legitima como categorias profissionais os "enfermeiros" e os "auxiliares de enfermagem", não fazendo referência à formação dos atendentes de enfermagem, majoritários nos serviços de saúde.

Assim, em 1956, existiam no país 33 escolas para enfermeiros e 41 cursos de auxiliares de enfermagem. A força de trabalho da categoria era composta por 42.931 trabalhadores sendo $11,3 \%$ enfermeiros, 4,6\% auxiliares de enfermagem e $84,1^{\circ} \mathrm{O}$ atendentes. (BARBOSA, 1991).

A Lei de Diretrizes e Bases da Educação Nacional, número 4.024 de 1961, cria as escolas técnicas de enfermagem destinadas aos que tivessem concluído os estudos do primeiro ciclo de nível médio, mantendo os cursos de enfermagem de nível superior e definindo os de auxiliares de enfermagem como nível ginasial. A criação do curso técnico de enfermagem acompanha a criação dos cursos técnicos do pais, decorrentes das necessidades de incorporação tecnológica surgidas com a expansão e modernização cio parque industrial brasileiro. As lideranças em enfermagem encaminharam a proposta e a defenderam.

$\mathrm{Na}$ área da saúde, o relatório da $3^{\mathrm{a}}$ Conferência Nacional, realizada em 1963, alertava que saúde era um direito social, portanto um dever do Estado para com toda a sociedade e propunha a descentralização e municipalização da administração dos serviços de saúde. Os delegados da conferência, representantes da sociedade civil e sanitaristas consideravam que quanto mais próximos da população, melhores seriam os serviços e melhor seriam aplicados e fiscalizados os recursos para a saúde. Este era um fundamento básico defendido pelo Movimento Municipalista, que cabia a todas as áreas sociais.

Até o fim deste período mantinha-se, no ensino da enfermagem, a concepção do condicionamento. Contudo, o ensino universitário traz em seu bojo um forte componente de transmissão do conhecimento e este é também incorporado pela enfermagem. Desta forma a enfermagem busca firmar-se como ciência tendo como modelo o currículo do curso médico e a valorização da assistência de enfermagem hospitalar centrada nos aspectos da atenção secundária aos pacientes.

\subsection{Quarto periodo: de 1965 a 1980.}

A partir de 1965, a politica educacional volta-se para reordenar as formas de controle social e politico. HA todo um aparelho repressor ideológico garantindo os interesses das classes hegemônicas. A Constituição de 1967 ampliou a obrigatoriedade do curso básico, gratuito e ministrado integralmente pela rede oficial de ensino de 4 para 8 anos e antecipou os parâmetros da Reforma Universitária (Lei 5.540/68), e da Reforma do Ensino de I e II graus (Lei 5.692/71), fundamentados nos princípios de que os estudantes devem estudar e os professores devem ensinar. (CHRISTÓFARO, 1992). Um instrumento utilizado para garantir a submissão do aluno foi a Lei 4.464/64 que proibia o funcionamento da União Nacional dos Estudantes, criada em 1937.

Os instrumentos legais de reforma do ensino reforçavam, no nivel médio, a tendência tecnicista enquanto a reforma universitária tendia A concepção humanista moderna ou escolanovismo, fundamentada nos princípios e parâmetros do Relatório Flexner, proposto para as escolas americanas em 1920. Os parâmetros do ensino universitário, segundo CHRISTÓFARO (1992), foram a departamentalização com a criação dos ciclos básicos por área de conhecimento (ciências humanas, exatas e biológicas); o sistema de créditos; as formas jurídico-administrativas múltiplas; o regime de tempo integral para professores; a criação de hospitais universitários; o vestibular unificado e classificatório; o estabelecimento de dois níveis de pós-graduação (mestrado e doutorado). 
As políticas de saúde vigentes no período de exceção resultaram na unificação dos IAPS's, com a criação do INPS (Instituto de Previdência e Assistência Social). O empregador e o trabalhador perdem o controle dos institutos de pensão que passam a ser controlados e gerenciados pelo governo federal.

Com a expansão da economia brasileira, aumentava cada vez mais o número de trabalhadores registrados que contribuiam com parcela de seus salários para a previdência social. Os empresários também contribuiam com a previdência social, contudo, embutiam este imposto no preço dos produtos que produziam. Pode-se assim afirmar que todos os brasileiros mantinham a previdência social, pois ao comprar qualquer produto para suas necessidades pagavam também o. imposto previdenciário repassado no preço do produto. No entanto, só os trabalhadores com "carteira assinada" e seus dependentes tinham direito aos beneficios do Instituto.

O INPS foi transformado em Ministério da Previdência e Assistência Social (MPAS) tornando-se, rapidamente, o ministério com os mais abundantes recursos. A opção do Estado Brasileiro em reação $A$ área da saúde, neste momento, foi utilizar estes recursos na compra de serviços, através de convênios. Na verdade, estes hospitais não existiam até então. Sua construção foi incentivada através de financiamento a fundo perdido pelo próprio governo federal, através dos recursos do Fundo de Assistência Social (FAS).

A ampliação da rede hospitalar - 25 hospitais próprios e 2.634 contratados na rede privada em 1970 (GOMES, 1991) ampliou a oferta de empregos para os trabalhadores de enfermagem. Dado à insuficiência e à incapacidade do sistema de formação das escolas de nivel médio em enfermagem em suprir o mercado, cerca de 300.000 atendentes, sem qualificação específica, foram incorporados ao setor da saúde exercendo, na maioria dos serviços de saúde, as mesmas atividades, reguladas, em lei, dos profissionais de enfermagem (SANTOS;SOUZA 1989).

Estes trabalhadores são parte da população marginalizada, excluida do sistema formal de educação. Como a saúde se tornou um bem de consumo e a rede privada objetiva sobretudo o lucro, não se investiu na qualificação em serviço deste contingente, explorado e espoliado econômica e fisicamente.

A assistência à saúde, prestada pelo Ministério da Previdência, centrada no modelo biológico, individual e recuperativo, aliada à insuficiente e inexpressiva ação, de prevenção e promoção da saúde a cargo do Ministério da Saúde, formaram no início dos anos 80 um perverso quadro cujas principais e graves conseqüências foram a desigualdade social Rev.Esc.Enf. USP, v.33, n.2. p. 165-74. jun. 1999. no acesso aos serviços de saúde; o estabelecimento de um modelo assistencial voltado para as ações curativas e individuais, centradas em hospitais públicos e privados; a desigualdade espacial pois a concentração dos hospitais se deu nos grandes centros urbanos, obrigando a população usuária a se deslocar por longas distâncias; os excessivos gastos com a rede hospitalar sem a correspondente resposta em qualidade e quantidade de serviços; a ausência de medidas de prevenção e promoção da saúde e manutenção de doenças facilmente evitáveis como: diarréia, tuberculose, hanseníase, malária, doença de Chagas, esquistossomose, tétano, sarampo, cárie dental entre outras (GOMES, 1991).

\subsection{Quinto periodo: as décadas de oitenta e noventa.}

A crise econômica que atingiu o mundo e o Brasil a partir de 1982 trouxe desemprego e, conseqüentemente, redução dos recursos arrecadados pela Previdência Social. Várias medidas foram tentadas para melhorar e expandir os serviços e as ações de saúde. No entanto o quadro sanitário do país se agrava: ao lado das doenças infecciosas surgem as chamadas doenças do primeiro mundo, como as doenças cardiacas, a hipertensão, o diabetes, o câncer.

Os conteúdos dos cursos da área de saúde, inclusive os de enfermagem, tanto em nivel superior quanto nos de nivel médio, buscavam qualificar profissionais para o modelo biomédico, curativo e individual. A ênfase do ensino de enfermagem continuava a girar em torno da assistência individual, hospitalar e curativa, revelando concordância das escolas com a demanda do mercado e a política do saúde predominante, Utilizando fundamentalmente a metodologia da transmissão e conhecimentos. (DOCUMENTO, 1989).

ALBUQUERQUE, em 1989, alertava que o objeto de trabalho dos enfermeiros caracterizava-se pela organização de espaço hospitalar e questionava que a enfermagem não pode se restringir ao papel de formar nobres e catedráticas zeladoras de espaços destinados às ações de saúde para o atendimento individual.

As escolas de graduação em enfermagem, na sua grande maioria, ao desconsiderar nos conteúdos programáticos o processo saúde-doença como determinante e determinado pelas condições de vida da população e o desenvolvimento das ações de enfermagem na prevenção e promoção da saúde coletiva e individual, reforçavam a prática profissional socialmente ineficaz da enfermagem. Ao mesmo tempo, apesar dos docentes conviverem com os atendentes no campo de prática, a reflexão sobre esta realidade não faz parte do cotidiano das salas de aula, até o início dos anos 80 . 
Métodos pedagógicos que influenciam o planejamento das ações educativas dos enfermeiros... Maria José Moraes Antunes et. al

O processo de redemocratização do País, a partir de meados dos anos 80 , coloca em pauta a discussão dos direitos da cidadania e do papel social do Estado. A sociedade brasileira, ao perceber o sistema de saúde esfacelado, fragmentado, inoperante e de má qualidade tenta reordená-lo e democratizá-lo. Surge o Movimento da Reforma Sanitária, que buscava institucionalizar seu projeto junto à VIII Conferência Nacional de Saúde (8' CNS), em 1986. Marco histórico, na área de saúde, este projeto ressaltava o reconhecimento da saúde como direito fundamental do ser humano, cabendo ao Estado prover todas as condições indispensáveis ao seu pleno exercício. Defendia o acesso universal e a assistência integral com predominância das ações de prevenção e promoção, com gestão descentralizada de base municipal e submetida ao controle social, através dos Conselhos de Saúde. (RELATÓRIO, 1986). A Constituição Federal de 1988 incorpora a parte das proposições da $8^{a} \mathrm{CNS}$ e regulamenta o Sistema Único de Saúde através das leis 8080/90 e 8142/90 (ANTUNES;BR ANT, 1994).

O processo de redemocratização o País também traz conseqüências para a área de educação. A Constituição Federal de 1988, estabelece no artigo $161:$

\begin{abstract}
".A educação é direito de todos e dever do Estado e da. família. Será promovida e incentivada com a colaboração da sociedade, visando ao pleno desenvolvimento da pessoa, seu preparo para o exercício da cidadania e sua qualificação para o trabalho. O dever do Estado com a educação será efetivado mediante a garantia de: (...) Ensino fundamental, obrigatório e gratuito, inclusive para os que a ele não tiveram. acesso na idade própria. (...) oferta de ensino regular, adequado às condições do trabalhador" (BRASIL, 1988).
\end{abstract}

$\mathrm{Na}$ enfermagem alguns fatos marcam profundamente a década de 80, tanto no ensino quanto na prática assistencial. No periodo registrase o processo de elaboração e implementação de uma proposta de novo currículo mínimo para o curso de graduação e a proposta de qualificação dos atendentes de enfermagem em auxiliares de enfermagem. Estas propostas trazem para a enfermagem a concepção pedagógica problematizadora, buscando integrar a teoria com a prática, o saber com o fazer. Não apenas como reflexão teórica, em cursos de graduação e pósgraduação, mas com prática metodológica. (CHRISTÓFARO, 1991).

Por outro lado, em 1986 o exercício profissional é regulamentado pela Lei 7498/86 que, formalmente, reconhece quatro categorias de profissionais de enfermagem: enfermeiros, técnicos de enfermagem, auxiliares de enfermagem e parteiras. Reconhece ainda a existência de pessoas que estão executando ações de enfermagem sem terem qualificação específica, por carência de recursos humanos de enfermagem de formação de nível médio. A mesma lei estabeleceu que estas pessoas receberão autorização do Conselho Federal de Enfermagem para continuarem exercendo atividades elementares de enfermagem por um período de dez anos.

A análise das propostas de treinamento em serviço em enfermagem no interior dos hospitais permite apontar que o referencial predominante é o funcionalista-taylorista voltado a favorecer a a daptação do funcionário à função (CAVALHEIRO; COLI, 1993).

Formados em uma concepção que bloqueia a reflexão crítica sobre a realidade e valoriza o saber intelectual, a medicina científica, e a administração taylorista, os trabalhadores de enfermagem e os enfermeiros, especialmente, têm dificuldade de adotar conteúdos e metodologias pedagógicas que incorporem à instrumentalização técnica-biológica a conscientização para o exercício de cidadania. Continuam buscando a competência técnica e o reconhecimento de seu espaço social sem a compreensão exata dos determinantes de sua força de trabalho que reproduz a realidade educacional e social brasileira, ou seja, grande percentagem de semi-analfabetos na base, os atendentes de enfermagem, e uma percentagem pouco significativa no ápice, os enfermeiros. Além disso utilizam práticas educativas junto aos usuários dos serviços de saúde que não consideram os interesses e necessidades de saúde enquanto qualidade de vida e de cuidados de enfermagem para além do referencial biológico, ou seja, não reconhecem a determinação social no processo saúde- doença.

No contexto nacional, segundo estimativas do Ministério da Educação, apenas 22\% dos alunos matriculados na primeira série completam a oitava série. Só 5\% conseguem concluir o primeiro grau sem repetir um ano. Nossa educação básica é a segunda pior do mundo, perdendo apenas para o Gabão, na África, segundo a UNICEF (Fundo das Nações Unidas pela Infância). Comparado com a média internacional, cios países da América Latina, o Brasil detém o recorde do menor número de matrículas no ensino de segundo grau. E segundo pesquisa da UNICEF, realizada em 129 países, o Brasil é o campeão mundial de analfabetismo, suplantando inclusive o Haiti, cuja renda per capita é 7 vezes menor que a nossa. (DIMENSTEIN, 1994).

Na saúde há expansão de programas derivados de políticas paliativas, voltados à atenção primária à população de baixa renda, como o Programa de 
Cesta Básica, o Programa de Agentes Comunitários de Saúde (PACS) e o Programa de Saúde da Família (PSF), com a inserção, apenas no período de 1994 a 1996, de cerca de 40.000 trabalhadores sem qualificação específica, executando ações de assistência a doentes sob a supervisão do enfermeiro. (BRASIL, 1997)

Em 1997 é estabelecida uma nova LDB para a educação. O entendimento de seus principios e diretrizes é fundamental para os educadores em geral e para a enfermagem em particular, porque propõe alternativas para a qualificação de trabalhadores adultos já inseridos no mercado de trabalho.

\section{CONSIDERAÇÕES FINAIS}

A trajetória das práticas educacionais e assistenciais de enfermagem, enquanto prática socialmente determinada pelo sistema vigente, tem atendido aos interesses econômicos, políticos e sociais do poder hegemônico conforme caracterizado nesta revisão bibliográfica.

Este estudo nos permite afirmar que a relação pedagógica entre professor e aluno, enfermeiro e equipe de enfermagem, enfermeiro e usuário dos serviços de saúde, é influenciada por fatores externos e anteriores ao momento do processo de ensino em si.

Estas influências são condicionadas por determinantes ligados à estrutura ideológica e econômica existente no País que afetam e são afetados pelo processo educacional predominante em um momento histórico e influenciam a organização do trabalho e do ensino em geral, inclusive os da enfermagem. As práticas educacionais de enfermagem têm contribuído para a manutenção do modelo médico-biológico de atenção à saúde, hegemônico no imaginário da sociedade, ao sustentar, na prática educativa junto aos usuários dos serviços de saúde. a organização de grupos a partir de patologias já instaladas (infectocontagiosas e crônico-degenerativas).

Tais grupos reforçam a manutenção das antigas instituições na assistência médica: controle medicamentoso e segregação dos seres humanos a partir de distúrbios fisicos e mentais, discriminandoos em sua integralidade. Em que pese a necessidade de controlar a evolução da patologia instalada em seus portadores para evitar complicações e agravamento dos casos, questiona-se se não haveria outra maneira de agrupar e acompanhar os seres humanos sem rotulá-los e segregá-los socialmente, nos serviços de saúde, pelo distúrbio que possam apresentar .
As propostas de educação continuada, nos serviços de saúde, parecem continuar voltadas para o "adestramento" e adaptação do funcionário à função, sem a incorporação de conteúdos e métodos que possibilitem ao trabalhador de enfermagem criar e recriar seu trabalho.

A avaliação das conseqüências das propostas de educação continuada e de educação para a saúde junto aos trabalhadores de enfermagem e à sociedade brasileira, atualmente desenvolvidas pelos enfermeiros, constituem-se em vasto campo para pesquisa em enfermagem.

\section{REFERENCIAS BIBLIOGRÁFICAS}

ALCANTARA, G. A cnfermagcm moderna como categoria profissional: obstáculos à sua expansão na sociedade brasileira. Ribeirão Preto, 1963.1251). Tese (Titular) - Escola de Enfermagem de Ribeirão Preto, Universidade de São Paulo.

ALBUQUERQUE, M.C. Situação de enfermagem na década de 80. In: CONGRESSO BRASILEIRO DE ENFERMAGEM, 41, Florianópolis, 1989. Anais, Florianópolis, Associação Brasileira de Enfermagem. Seção Santa Catarina, 1989. p.76-83.

ALMEIDA, M. C. P. ; ROCHA, J. S. Y. O saber de enfermagem e sua dimensão prática. São Paulo, Cortez, 1986.

ANTUNES, M.J.M;BRANT, M.J.G.C. Ideologias c concepções pcdagógicas: influência na educação e na prática de Enfermagem. Belo Horizonte. 1994. / Mimeografado/

BARBOSA, J.K. A profissionalização do atendentc: um pressuposto para melhorar a qualidade da assistência de enfermagem. Curitiba, 1991 Dissertação (Mestrado) Universidade Federal do Paraná. 1991.

BORDENAVE, J.E.D. Alguns fatores pedagógicos. Caderno do Módulo Pedagógico. Curso de Especialização de Enfermeiros em Saúde Pública. UFMG. DEMISP. 1989.

BRASIL. Constituição, 1988. Constituição da República Federativa do Brasil, 1988. Brasília, 1988. Título VIII: Da ordem Social, 1).131-7.

BRASIL. Ministério da Saúde. Programa Comunidade Solidária. Programa de agentes de saúde. Brasília, 1997.

CAVALHEIRO, E.R.A.; COLI R, C.P. Treinamento em enfermagem. Rev.Paul.Enf. v. 12, n.2, p. 57-9, 1993.

CHRISTÓFARO, M.A.C. Processo de formação em enfermagem no Brasil. /Trabalho apresentado no $40^{\circ}$ Congresso Brasileiro de Enfermagem, Belém, 1988/.

Curriculum minimo para a formação do enfermeiro: na ordem do dia. Rcv. Bras. Enf., v.44, n.2/3, p.7-9. 1991. 
Métodos pedagógicos que influenciam o planejamento das ações educativas dos enfermeiros... Maria José Moraes Antunes et. al - A Organização do sistema educacional GOMES, E.L.R. Administração em enfermagem brasileiro e a formação na área de saúde. Brasília. 1992. Mimeografado/

DIMENSTEIN. G. Saúde brasileira é cara e sucateada. Folha de São Paulo. São Paulo, 31 jul. 1994. Caderno Brasil 95 Especial A, 9 constituição histórico - social do conhecimento. São Paulo, 1991. 188p. Tese (Doutorado) - Escola cie Enfermagem, Universidade de São Paulo.

RELATÓRIO final. In: CONFERENCIA NACIONAL DE SAÚDE, 8, Brasília, 1986. Anais. Brasília, 1986.1).381-9

DOCUMENTO final. In: CONGRESSO BRASILEIRO DE ENFERMAGEM， 41, Florianópolis. 1989. Anais. Florianópolis. ABEn. 1989..p. 181-8.

SANTOS, I.; SOUZA, A.M. Formação de pessoal de nível médio pelas instituições cie saúde: projeto larga escala uma experiência em construção. Saúdc Debate, n.24,1).61-4. 1989

FREIT AG. B. Escola, Estado \& Sociedade. G. ecl. São Paulo, Moraes, 1986.

TEIXEIRA. S.M.F. Politica de saúde na transição conservadora. Saúde Debate, n.26, p.42-53, 1989.

GADOTTI. M. História das Idéias pedagógicas. 5. ecl. São Paulo. Ática. 1997. 